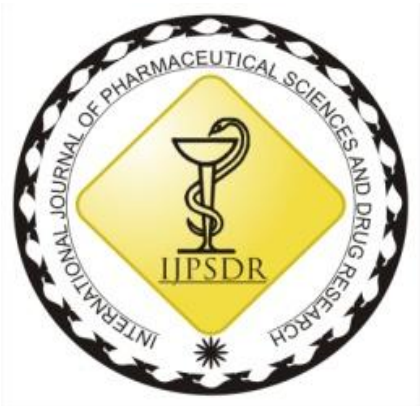

ISSN: 0975-248X

RESEARCH ARTICLE CODEN (USA): IJPSPP

$($ (c) $)$ EY-NC-SA

\title{
Identification of Phenyl Alanine Ammonia Lyase Gene Involved in the Synthesis of Anacardic Acid in Anacardium occidentale L.
}

\author{
S. L Sija* \\ Department of Biotechnology, Sree Narayana College, Kollam - 691 001, Kerala, India
}

Copyright (C) 2019 S. L Sija et al. This is an open access article distributed under the terms of the Creative Commons Attribution-NonCommercialShareAlike 4.0 International License which allows others to remix, tweak, and build upon the work non-commercially, as long as the author is credited and the new creations are licensed under the identical terms.

\begin{abstract}
Anacardic acids, a class of medicinally and industrially important phenolic compounds is found in a variety of dicotyledonous families chiefly in Cashew (Anacardium occidentale L). Phenylalanine ammonia-lyase (PAL) shows a dominant role in the biosynthesis of poly phenolic compounds, which are involved in the defense mechanism in harsh environments related to various stimuli. The current study was conducted to find out the presence of anacardic acid in ethyl acetate extract of young leaves of cashew using high performance thin layer chromatography (HPTLC) method and the presence of phenyl alanine ammonia lyase gene also plays a role in the biosynthesis of anacardic acid in young leaves was also confirmed by cDNA synthesis from a cellular mRNA template connected to the polymerase chain reaction (PCR).
\end{abstract}

Keywords: Anacardium occidentale, Anacardic acid, PAL, HPTLC, PCR.

DOI: 10.25004/IJPSDR.2019.110402

Int. J. Pharm. Sci. Drug Res. 2019; 11(4): 116-119

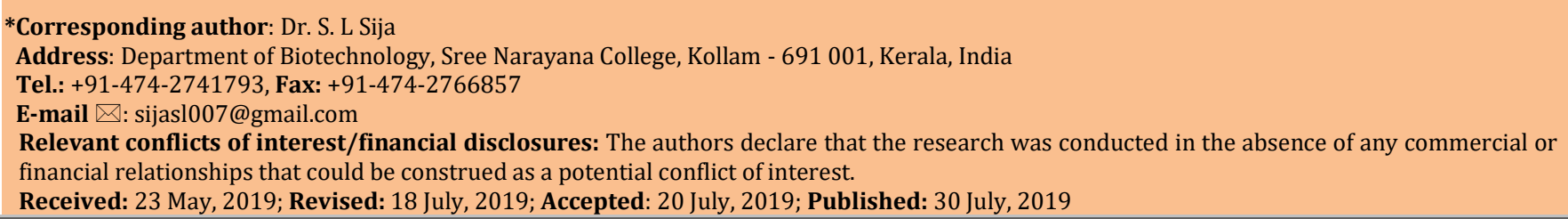

\section{INTRODUCTION}

Anacardium occidentale is a plantation crop belonging to the family Anacardiaceae. It is native to Brazil, from where it spread widely in the tropical countries from West to East Africa and India. [1] It is a multi-purpose plant. [2] Two most important parts in commercial uses are cashew nut and liquid from nut shell (CNSL). Several groups of phytochemicals have been found in different parts of A. occidentale. The phenolic compounds comprising anacardic acid was mainly concentrated in nut shell though it is seen throughout the plant body. ${ }^{[3-4]}$ Anacardic acid is also having very much demand in medical and industrial field. [5]
Anacardic acid has very much demand in the international market. [6] In medical field, it has been favorably used for the treatment of various diseases like ringworms, elephantiasis, warts etc. and also used in beauty therapy. It shows antiviral activity, antibacterial activity, antifungal activity, antiinflammatory activity, antioxidant activity [7], anticarcinogenic ${ }^{[8]}$ activity etc. In industrially, it is used as a raw material for corrosion resistant varnishes, synthetic resins, brake lining compounds of automobiles, heat and water proof paints, insulating enamels for the electrical industry etc. [9] 
Little information concerning the genes involved in the biosynthetic enzymes of the polyketide or acetate pathway for anacardic acid has been published. Phenylalanine ammonia-lyase (PAL) plays an important part in the biosynthesis of poly phenolic compounds, which are involved in the defense mechanism related to different stimuli. This enzyme catalyzes the deamination of phenylalanine which leads to the formation of trans-cinnamic acid and ammonia; it is the initial step in the synthesis of phenolics. [10] Many reports highlight on the relationship between increase in the comparable PAL gene activity and increase in the phenolic compounds in reaction to various external stimuli. [11] The major phenolic lipids such as anacardic acid, anacardols, cardols and their isomers are produced by going through the phenyl propanoid pathway in Anacardium. Activity of PAL gene has been determined from many plant species but not from A. occidentale. There has been no published report regarding the genes responsible for the production of anacardic acid in cashew. In view of the role of anacardic acid in curing many infections and based on their antioxidant and anticancerous properties, the current study was carried out to give a precised picture on the estimation of anacardic acid in cashew leaves by HPTLC and the detection of phenyl alanine ammonia lyase gene responsible for the production of anacardic acid in young leaves of cashew by polymerase chain reaction (PCR) amplification.

\section{MATERIALS AND METHODS}

\section{Source of plant materials}

Mature cashew seeds were collected from the mother trees growing at the Kerala State cashew development corporation, Mundakkal, Kollam, Kerala. The explants used in this study were micro leaves, which sprouted from cotyledonary node axils of decapitated seedlings germinated in plastic trays containing sterilized sand.

Preparation of plant extracts for HPTLC

Young leaves of A. occidentale were air dried and powdered. It was extracted with ethyl acetate at room temperature for 24 hours at a ratio of 1:100 (g: ml). Samples were then centrifuged at 10,000 rpm for $15 \mathrm{~min}$ and supernatants were collected and dried. Residue was dissolved in ethyl acetate and stored at $4-8^{\circ} \mathrm{C}$ in a refrigerator.

\section{HPTLC estimation of anacardic acid}

HPTLC analysis was carried out on Camag HPTLC. Anacardic acid (Sigma Aldrich) was used as the standard $(100 \mu \mathrm{g} / \mathrm{ml})$. Twin trough chamber was used for separation using the solvent system as mobile phase [chloroform: ethyl acetate (9:1)] and the HPTLC settings were - Band length $8 \mathrm{~mm}$, distance between track $15 \mathrm{~mm}$, slit dimension $-6.00 \mathrm{~mm} \times 0.45 \mathrm{~mm} \times$ micro, scanning speed- $20 \mathrm{~mm} / \mathrm{s}$; data resolution$100 \mu \mathrm{m} / \mathrm{step}$. Qualitative analysis was carried out by TLC scanner 3 Camag HPTLC systems by comparing the peak area values of sample with that of standard using the Wincats software at wavelength $305 \mathrm{~nm}$.
Molecular detection of phenyl alanine ammonia lyase gene

\section{mRNA Isolation}

Total RNAs were isolated using the RNeasy Plant MiniKit (Qiagen Science, Maryland USA). With a mortar and pestle $100 \mathrm{mg}$ of sample was homogenized in $450 \mu 1$ of RLT buffer. The homogenate was poured into the QIA shredder column (purple) and centrifuged at 10,000 rpm for $1 \mathrm{~min}$. The supernatant were pooled and mixed with 0.5 volumes $(225 \mu \mathrm{l})$ of absolute ethanol. The resulting mixture was applied onto the RNeasy column (pink) and centrifuged at 10,000 rpm for $1 \mathrm{~min}$. The supernatant were discarded. The column was washed with $450 \mu 1$ RW1 buffer by centrifugation at

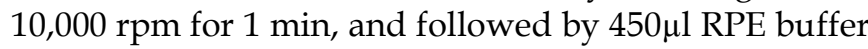
as the same manner. The total RNAs was eluted with $30 \mu 1$ Rnase-free water by applying on top of the column and left for one min, then centrifuged at 10,000 rpm for $1 \mathrm{~min}$. The eluted RNAs were further used for cDNA synthesis.

cDNA Synthesis and PCR Amplification

A cDNA was synthesized using QIAGEN one-step RTPCR kit. The total $20 \mu 1$ reaction was prepared by aliquot $1 \mu 1$ of total RNAs solution, $1 \mu 1$ of $20 \mu \mathrm{M}$ forward primer, $1 \mu \mathrm{l}$ of $20 \mu \mathrm{M}$ reverse primer, $4 \mu \mathrm{l}$ of $5 \mathrm{X}$ RTbuffer, $0.8 \mu \mathrm{l}$ of $10 \mathrm{mM}$ dNTPs, $0.8 \mu 1$ of enzymes and $11.4 \mu \mathrm{l}$ Rnase-free water. Synthesis of cDNA was performed on the Biometra thermalcycler (Germany) at $50^{\circ} \mathrm{C}$ for $30 \mathrm{~min}$ and followed by denaturation at $95^{\circ} \mathrm{C}$ for $15 \mathrm{~min}$.

For the PCR reaction the forward primer used for the PAL gene was AATGGCTCCCCAAAAAATAGAAA and the revers primer sequence was GTTGGAACAAATGCGGGTCT. Each of forward and the revers primers were used to amplify about $350 \mathrm{bp}$ of the cDNA. ${ }^{[1]}$ The forward and revers primers were designed using the gene bank (ncbi.Org). Master Mix (DreamTaq TM green PCR Master Mix (2x) containing (DNA polymerase + optimized green buffer $+\mathrm{MgCl}_{2}$ and dNTPs). The PCR amplification was carried at the initial denaturation at $94^{\circ} \mathrm{C}$ for $3 \mathrm{~min}, 35$ cycles of denaturation $94^{\circ} \mathrm{C}$ for $30 \mathrm{sec}$, annealing at $55^{\circ} \mathrm{C}$ for 30 sec extension at $72^{\circ} \mathrm{C}$ for $30 \mathrm{sec}$, and a final extension at $72^{\circ} \mathrm{C}$ for $5 \mathrm{~min}$.

\section{Gel Electrophoresis of PCR Products}

The amplification was confirmed on $1 \%$ agarose gel by gel electrophoresis. A $1 \mathrm{~kb}+$ ladder (New England Biolabs, Inc., MA,USA) was loaded along with the PCR products. An aliquot of $5 \mu$ from $20 \mu$ l PCR reaction volume was mixed with $3 \mu$ of loading buffer and then loaded to each gel. The gels were run in a mupid geltang at $100 \mathrm{~V}$ for $40 \mathrm{~min}$. Gels were stained with ethidium bromide $(0.5 \mu \mathrm{l} / \mathrm{ml})$ for $10 \mathrm{~min}$ and washed with water for few second. DNA was visualized using UV transilluminator (UPV, CA, USA).

\section{RESULTS AND DISCUSSION}

Estimation of anacardic acid by HPTLC 

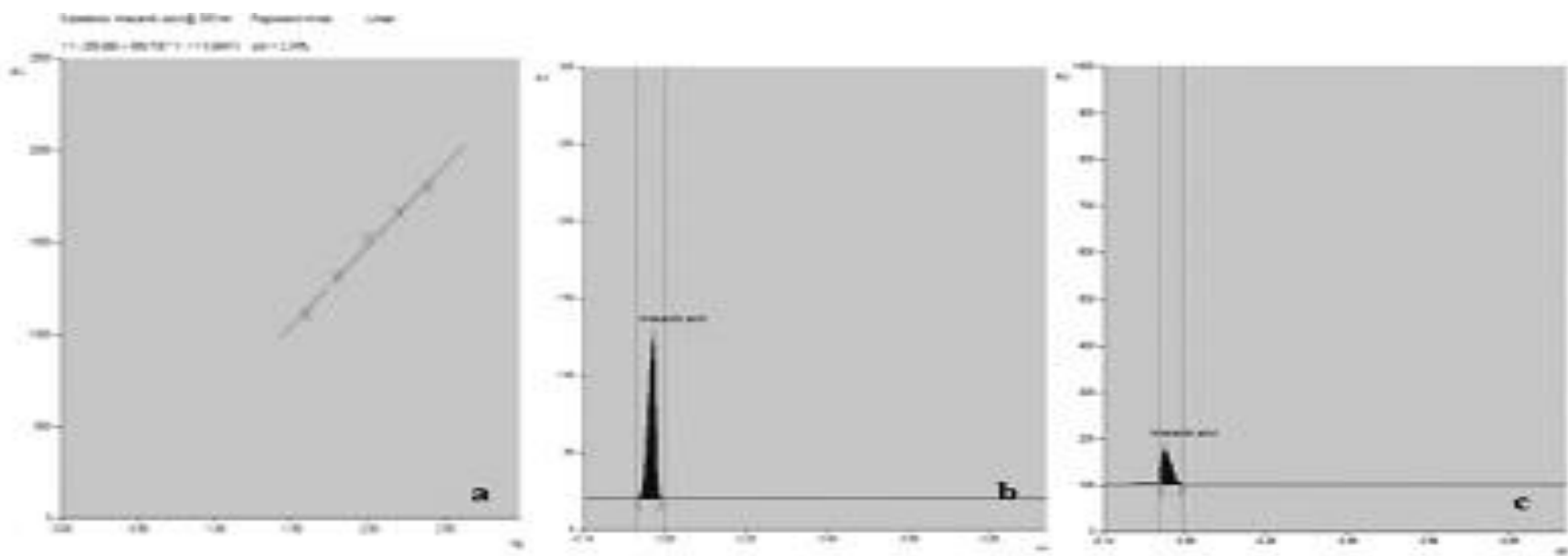

Fig. 1: a) Calibration curve of standard anacardic acid; b): HPTLC chromatogram of standard anacardic acid; c) HPTLC chromatogram of young leaves

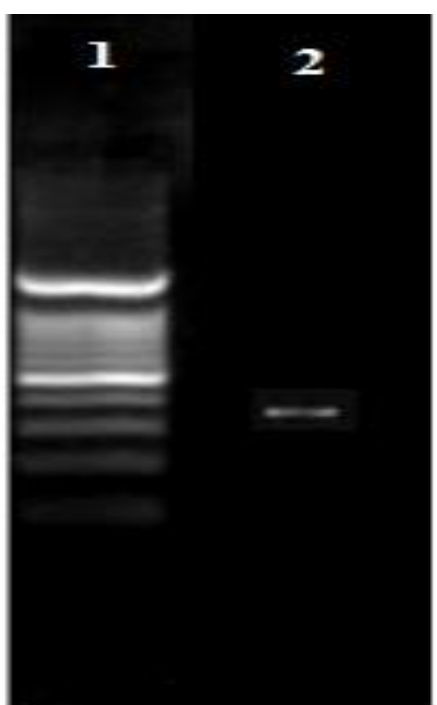

Fig. 2: Agarose gel electrophoresis of PCR amplified products. Lane 1:- 1 kbDNA ladder; Lane 2:- sample (cashew leaves)

Qualitative evaluation of anacardic acid was done by HPTLC. Chloroform: ethyl acetate (9:1) (v/v) was used as the mobile phase. The current study showed that the presence of anacardic acid in young leaves from seedling. Calibration curve and HPTLC chromatogram of standard anacardic acid were conferred in fig. $1(\mathrm{a}, \mathrm{b})$. HPTLC chromatogram of young leaves of A. occidentale was also obtained (Fig. 1c). HPTLC technique is one of the best tools for identification and authentication of plant secondary metabolites. [12] It was also reported the presence of anacardic acid in cashew nut shell liquid, cashew nut and cashew fruit. [13-16]

Molecular detection of phenyl alanine ammonia lyase gene

mRNA was isolated from the young leaves of cashew using RTPCR. cDNA was synthesized from cellular mRNA template. Presence of phenyl alanine ammonia lyase gene in cashew leaves was confirmed by PCR amplification using the primer [Forward Primer Name: F: AATGGCTCCCCAAAAAATAGAAA

Reverse Primer Name:

R: GTTGGAACAAATGCGGGTCT]
Gel electrophoresis revealed that the bands are found between 300 and $400 \mathrm{bp}$. This is consistent with the 350 bp. Plant phenolics are the secondary metabolites produced from either the shikimate pathway or the malonate pathway. [17] Molecular cloning, characterization and expression of the phenylalanine ammonia-lyase gene from some tree species like Juglans regia and Eucalyptus robusta were also reported. [18-19]

The present investigation proved the presence of medicinally and industrially important anacardic acid in young leaves of cashew by HPTLC technique and also confirmed the presence of phenyl alanine ammonia lyase gene carried out in the synthesis of anacardic acid in the tender cashew leaves by cDNA synthesis from a cellular mRNA template connected to the polymerase chain reaction (PCR).

\section{ACKNOWLEDGEMENT}

I sincerely acknowledge Dr. P. S. Santhoshlal, Associate Professor (Rtd.), Dept. of Botany \& Biotechnology, Sree Narayana College, Kollam, Kerala, India for his extended support and guidance. I thankful to the CEPCI Laboratory and Technical Division, Cashew Bhavan, Kollam- 691 001, Kerala, India and UniBiosys Biotech Research Labs, Cochin, Kerala, India for providing the laboratory facilities to carry out the present work.

\section{REFERENCES}

1. Mitchell JD, SA Mori. The cashew and its relatives (Anacardium: Anacardiaceae). Mem. New York Bot. Gard. 1987; 42: 1-76.

2. Togun A. A review of the prospect of cashew industry. Cocoa Research Institute of Nigeria. 1977; 100-110.

3. Ojezele MO, Agunbiade S. Phytochemical constituents and medicinal properties of different extracts of Anacardium occidentale and Psidum guajava. Asian Journal of Biomedical and Pharmaceutical Sciences. 2013; 3 (16): 20-23.

4. Paramashivappa R, Phanikumar NP, Vithayathil PJ, Sreenivasa RA. Novel method for isolation of major phenolic constituents from cashew (Anacardium occidentale L.) nut shell liquid. J. Agri. Food Chem. 2003; 149: 2251-2548.

5. Pillai CKS, Prasad VS, Sudha JS, Bora SC, Menon AAR. Polymeric resins from renewable resources. J. Applied Sci. 1990; 4: 2487-2501. 
S. L Sija et al. / Identification of Phenyl Alanine Ammonia Lyase Gene Involved in the Synthesis.

6. Rodrigues FHA, Feitosa JPA, Ricardo NMPS, de Franca FCF, Carioca JOB. Antioxidant activity of cashew nut shell liquid (CNSL) derivatives on the thermal oxidation of synthetic cis1, 4-polyisoprene. Journal of the Brazilian Chemical Society. 2006; 17: 265-271.

7. Abas F, Lajis N, Israf D, Khozirah S, Umi KY. Antioxidant and nitric oxide inhibition activities of selected Malay traditional vegetables. Food Chemistry. 2006; 95(4): 566-573.

8. Singleton VL, Orthofer R, Lamuela-Raventos RM. Analysis of total phenols and other oxidation substrates and antioxidant by means of Folin-Ciocalteu reagent. Method. Enzymol. 1999; 299:152-178.

9. Menon ARR, Pillai CKS, Sudha JD, Mathew AG. Cashew nut shell liquids, its polymeric and other industrial products. J. Sci. Ind. Res. 1985; 44: 324-338.

10. Hahlbrock K, Scheel D. Physiology and molecular biology of phenyl-propanoid metabolism. Annu. Rev. Plant Physiol. Plant Mol. Biol. 1989; 400: 347-369.

11. El-Naggar HM, Read PE. PAL Gene Activity and Rosmarinic Acid production in Rosemary Genotypes. J. Herbs. Spices. Med. Plant. 2010; 16: 83-89.

12. Harish CA, Vijay KP. High Performance Thin Layer Chromatography (HPTLC): A modern analytical tool for biological analysis. Nature and Science. 2010; 8(10): 58-61.
13. Sabna PS, Potty VP. Thermal stability of CNSL by TGA and HPTLC. International Journal of Biotechnology and Biochemistry. 2011; 7 (5): 607-616.

14. Praveen Kumar SN, Bhadre Gowda DG, VathsalaDeepu C, Mantelingu K, Rangappa KS. Development and validation of a normal phase HPLC method for separation of anacardic acid isomers in cashew nut shell liquid. Journal of Chemical and Pharmaceutical Research. 2013; 5(5):369-373.

15. Trevisan MTS, Pfundstein B, Haubner R, Wurtele G, Spiegelhalder B, Bartsch H, Owen RW. Characterization of alkyl phenols in cashew (Anacardium occidentale) products and assay of their antioxidant capacity. Food and chemical toxicology. 2006; 44(2): 188-197.

16. Kubo I, Masuoka N, Ha TJ, Tsujimoto K. Antioxidant activity of anacardic acids. Food Chem. 2006; 99: 555-562.

17. Manitto P, Sammes PG. Biosynthesis of Natural Products; Wiley: New York, 1981.

18. Feng $x$, Guang D, Shuiyuan C, Weiwei $Z$, Xiaohua $H$, Linling L. Molecular Cloning, Characterization and Expression of the Phenylalanine Ammonia-Lyase Gene from Juglans regia. Molecules. 2012; 17: 7810-7823.

19. Shinya A, Takahisa I, Tamami T, Masahiro, Shigehiro K. A phenylalanine ammonia-lyase gene (ErPAL1) from Eucalyptus robusta: molecular cloning, expression and characterization. Bull. Univ. of Tokyo For. 2013; 128: 121-137.

HOW TO CITE THIS ARTICLE: Sija SL. Identification of Phenyl Alanine Ammonia Lyase Gene Involved in the Synthesis of Anacardic Acid in Anacardium occidentale L. Int. J. Pharm. Sci. Drug Res. 2019; 11(4): 116-119. DOI: 10.25004/IJPSDR.2019.110402 